\title{
AIDS Treatment In Brazil: Impacts And Challenges
}

Brazil's accomplishments in treating AIDS are unprecedented and have profoundly influenced global AIDS and health policy.

\section{by Amy Stewart Nunn, Elize Massard da Fonseca, Francisco I. Bastos, and Sofia Gruskin}

ABSTRACT: Brazil has one of the developing world's largest, and arguably most successful, AIDS treatment programs. In this paper we review the treatment program, including controversial policies that Brazil has used to promote widespread local and global access to AIDS treatment. We also examine the lessons learned from this program and highlight the challenges Brazil faces, including the rising costs of AIDS treatment and changes in donors' funding priorities. Finally, we explore the relevance of Brazil's treatment program for other countries and its broad implications for global AIDS and health policy. [Health Affairs 28, no. 4 (2009): 1103-1113; 10.1377/hlthaff.28.4.1103]

I N 2009, thirty-Five million people are living with HIV/AIDS. Although HIV/AIDS has become a chronic, treatable illness in developed countries because of life-saving drug cocktails, or highly active antiretroviral therapy (HAART), millions of people in the developing world still lack access to treatment. In recent years many countries have made dramatic progress in providing drugs to treat people living with HIV/AIDS. In 2003 approximately 300,000 people received AIDS treatment; by 2009 four million of the ten million people needing HAART in developing countries received it. Much of this progress can be traced to Brazil's efforts to promote global AIDS treatment.

Education and prevention efforts. Since the 1980s, Brazil has implemented HIV education and prevention campaigns, including nationwide condom distribution and HIV testing, as well as prevention campaigns targeting vulnerable populations such as sex workers, injecting drug users, and men who have sex with men (MSM). However, Brazil's National STD and AIDS Program (hereafter NAP) is best

Amy Nunn (amy_nunn@brown.edu) is an assistant professor of medicine (research), Division of Infectious Diseases, at Brown University in Providence, Rhode Island. Elize Massard da Fonseca is a doctoral candidate at the School of Social and Political Science, University of Edinburgh, in Scotland. Francisco Bastos is chair of Graduate Studies in Epidemiology at the National School of Public Health, Oswaldo Cruz Foundation, in Rio de Janeiro, Brazil. Sofia Gruskin is director of the Program on International Health and Human Rights and an associate professor in the Department of Global Health and Population, Harvard School of Public Health, in Boston, Massachusetts. 
known for its controversial, highly successful treatment initiatives. Throughout the 1990s, when the annual cost of drugs for AIDS treatment often exceeded US $\$ 10,000$ per patient, the World Bank and other development agencies discouraged developing countries from implementing treatment programs, favoring "cost-effective" prevention over costly treatment. Brazil challenged this conventional wisdom and, despite World Bank objections, has provided free universal access to HAART for all people living with HIV/AIDS since 1996.

- Brazil's achievments. Brazil's accomplishments won international acclaim and are credited with dramatically reducing AIDS-related mortality and morbidity, including mother-to-child transmission of HIV. ${ }^{1}$ Brazil achieved these remarkable outcomes through several creative strategies: producing generic AIDS medicines in public drug factories; threatening to produce generic versions of patented medicines to induce steep price reductions from multinational pharmaceutical companies; shaping global AIDS and drug policy to support its domestic policies; and supporting local and global civil-society engagement. Here we examine lessons from Brazil's experience, explore implications for responding to the AIDS pandemic elsewhere, and highlight future challenges. Our findings are empirically grounded in ninetyone interviews, a review of more than 2,000 Brazilian news articles since 1985, and other historical information.

\section{HIV/AIDS In Brazil And The Public Policy Response}

- Prevalence. Brazil has a concentrated epidemic: in 2009 HIV prevalence is 0.5 percent, and approximately 660,000 people live with HIV/AIDS. Prevalence in Brazil's rural areas remains very low. Although AIDS prevalence and incidence continue to rise in Northeastern Brazil and among vulnerable populations such as men who have sex with men, the urban poor, and injection drug users, the epidemic has largely stabilized. ${ }^{2}$ Combination drug therapy, or HAART, is now offered in hundreds of clinics nationwide; the number of people receiving HAART in Brazil has increased from 35,000 in 1997 to 185,000 today, representing nearly all of those currently needing treatment.

Response. Brazil has implemented diverse strategies for securing AIDS drugs. Notably, the federal Health Ministry has financed production and procurement of drugs for AIDS treatment and has produced generic AIDS medicines since the early 1990s. In 1996 Brazil's Congress passed a law guaranteeing free, universal access to drugs for AIDS treatment. It also passed the 1996 Industrial Property Law, which brought Brazil into compliance with World Trade Organization (WTO) rules requiring middle-income and least-developed countries to introduce local intellectual property (IP) regulations by 2005 and 2016, respectively. The Industrial Property Law introduced patent rights for pharmaceuticals, guaranteeing drug companies exclusive marketing rights for their products. It limited government production of generic drugs to those introduced in the Brazilian marketplace before 1997. All pharmaceuticals introduced after 1996 enjoy patent protection, resulting in higher prices 
for many of the antiretrovirals (ARVs) that are currently available. Introducing several new patented ARVs into treatment, coupled with rising numbers of people seeking treatment (Exhibit 1), caused AIDS treatment costs to spike in the late 1990s. ${ }^{3}$

Rising costs prompted the Brazilian government to explore additional strategies to meet its guarantee of access to AIDS treatment. ${ }^{4}$ In 2000 Health Minister José Serra began publicly threatening to issue a compulsory license for local production of generic versions of patented ARVs. This controversial move prompted the United States to file a WTO trade dispute against Brazil in 2001. In the wake of protests by the global AIDS movement and the subsequent public relations disaster, the United States dropped its WTO dispute, and several multinational pharmaceutical companies slashed the prices of AIDS medicines.

Since 2001 Brazil has produced generic copies of medicines introduced prior to 1997 and has used the threat of compulsory license and domestic production to induce deep discounts from innovator pharmaceutical companies. In 2007 Brazil issued its first compulsory license to import efavirenz, a drug currently under patent in Brazil and the most commonly prescribed ARV in Brazil's AIDS treatment guidelines, from an Indian manufacturer. In 2008 Brazil's patent office rejected the patent for the ARV tenofovir, and the country is expected to import generic tenofovir in 2009. Brazil also began producing efavirenz locally in 2009.

\section{Lessons From Brazil's AIDS Program}

Much can be learned from Brazil's experience. Brazil helped shape global AIDS treatment norms and donor policies in several important ways. We next explore lessons that can be applied in other settings.

Strong civil society and public policy responses are critical for improving treatment access. The AIDS movement emerged during Brazil's transition to democracy in the late 1980s and early 1990s. Using media strategies and public protests to demand responses to the AIDS crisis, nongovernmental organizations

\section{EXHIBIT 1}

Patients Receiving Highly Active Antiretroviral Therapy (HAART) In Brazil, 1997-2008

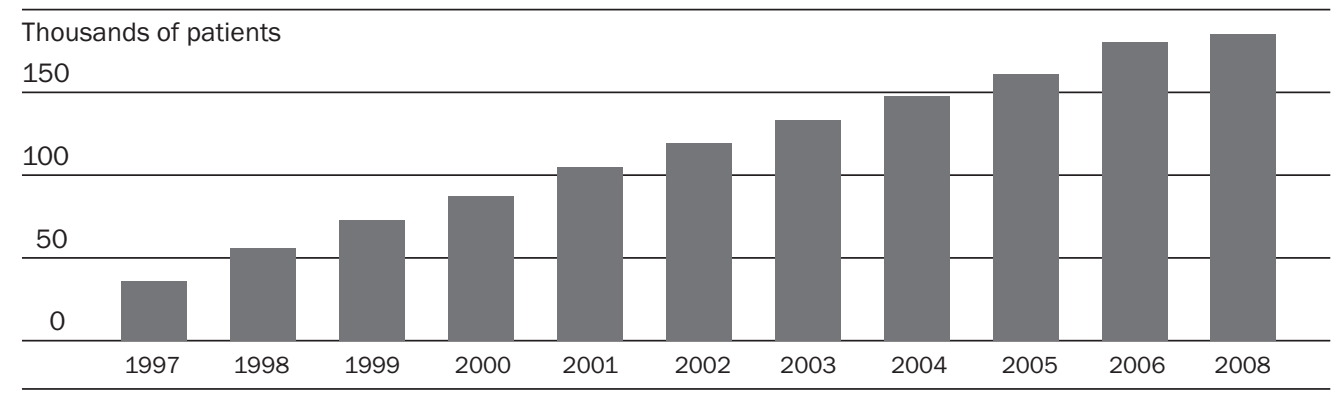

SOURCE: National STD and AIDS Program of Brazil, 2008.

NOTE: Data for 2007 were not provided by the Ministry of Health. 
(NGOs) formed and demanded that the government adopt antidiscrimination policies, implement prevention and education programs, and provide AIDS treatment and care. Most notably, NGOs such as Associação Brasileira Interdiciplinar de AIDS (ABIA) and Grupo pela Valorização, Integração e Dignidade do Doente de Aids (Pela VIDDA) used the courts to gain legal recognition that the right to health as enshrined in the 1988 Constitution includes rights to prevention, treatment, and care for people living with HIV/AIDS. Brazil's courts have consistently ruled that the right to health includes drugs for AIDS treatment. ${ }^{5}$

The NAP has couched its programs in human rights terms and has consistently included outreach to vulnerable populations. It is renowned for partnering with NGOs in developing and implementing programs through civil-society partnerships. Brazil's tradition of such partnerships began early in the epidemic, when NGOs such as Grupo de Incentivo à Vida (GIV) and Grupo de Apoio à Prevenção à AIDS (GAPA) implemented education and prevention campaigns to reduce stigma and discrimination, which encouraged people with HIV/AIDS to present for treatment. Others such as Viva Cazuza, a service organization for children with HIV, provide direct care for people with HIV/AIDS. Members of the NGO network Associação Brasileira de Redutoras e Redutores de Danos provide needleexchange and harm-reduction services for injecting drug users. Brazil's success can be attributed in part to this history of collaboration with civil society.

Brazil's treatment policies, including its reaction to international donors' spending restrictions, is also notable. For example, Brazil has received US $\$ 425$ million in World Bank loans since 1994. These loans played a key role in subsidizing the NAP, including health infrastructure and human resources development, HIV/AIDS surveillance, and prevention programs. However, World Bank policies strictly forbade spending on drugs for AIDS treatment. Brazil accepted the loans and, over the objections of the World Bank, used local resources to finance and implement the first large-scale developing-world AIDS treatment program.

The last five-year loan, valued at \$US100 million during 2004-2007, helped integrate the NAP into Brazil's broader public health infrastructure and decrease dependency on external resources. World Bank loans played a key role in subsidizing the NAP and health infrastructure development. However, as AIDS spending grew, those loans accounted for a declining share of NAP spending and only approximately 2 percent of total AIDS spending in Brazil in 2007.6 Although NAP might never have fully developed without World Bank support, these trends demonstrate Brazil's early and enduring commitments to AIDS.

Brazil's early public policy response, its consistent efforts to destigmatize HIV/ AIDS, the courts' expansive interpretation of the right to health, strategic use of foreign aid from the World Bank, and the government's long-term commitments to AIDS treatment can be attributed to Brazil's AIDS movement. This suggests that countries with vibrant civic activity and organized AIDS movements are best poised to respond to the epidemic. 
- Innovative strategies to promote access to drugs can lower AIDS treatment costs. Beginning in 1993, Brazil dramatically reduced treatment costs by producing several generic ARVs locally. Domestic production increased greatly in the late 1990s, as more patients sought treatment and Brazil developed infrastructure to provide treatment in clinics nationwide. Brazil's threats to issue compulsory licenses also prompted steep price declines for patented ARVs. Since 2001, the pharmaceutical companies Roche, Gilead, Merck, Abbott, and Bristol-Myers Squibb have dropped their ARV prices in Brazil and introduced tiered pricing in many developing countries. Price negotiations saved the Brazilian health ministry \$US1.2 billion in AIDS treatment costs in recent years. ${ }^{7}$

Threatening to issue compulsory licenses is a unique strategy. Few developing countries have public drug production capacity or requisite political will (including political engagement at the highest levels, vocal media, and strong support from local and global civil-society organizations) to challenge drug companies about prices. Brazil's strategies are not widely replicable, but they established precedents for developing countries to challenge drug companies and pursue other novel approaches to promote affordable access to medicines - strategies other nations have since adopted. Price challenges also increased transparency about global drug prices and prompted global policy dialogue about affordable access to treatment.

Using global channels can help normalize AIDS treatment in resourcelimited settings. When international donors were skeptical about feasibility and cost-effectiveness of AIDS treatment, Brazil's program provided evidence that treatment was affordable and feasible with limited resources. Brazil's success lent legitimacy to other developing countries' efforts to promote AIDS treatment. This evidence, coupled with a global AIDS treatment movement and support from other governments, prompted dramatic shifts in global AIDS policy.

Brazil's efforts to change international norms concerning access to essential medicines deserve special mention. Since 2001, to preserve its domestic treatment policies, it has engaged in consistent, concerted efforts to change international health, human rights, and trade policies related to essential medicines. Brazil led efforts to add ARVs to the World Health Organization (WHO) Essential Medicines List and improve transparency about global drug prices; sponsored the WHO resolution to establish the Global Fund to Fight HIV/AIDS, Tuberculosis, and Malaria; and spearheaded efforts to change global research and development (R\&D) paradigms to bring medicines and diagnostics to market that disproportionately affect developing countries. Additionally, Brazil's efforts culminated in four United Nations Commission on Human Rights resolutions that recognize drugs for AIDS treatment as part of the human right to health. Brazil also led efforts to increase the flexibility of the WTO Trade-Related Aspects of Intellectual Property Rights (TRIPS) for developing countries to improve access to medi cines. $^{8}$ 
Brazil's efforts helped make AIDS treatment more available around the world. The Global Fund, which was created in 2001, has spent nearly $\$ 11$ billion for HIV/AIDS, TB, and malaria programs in more than 100 countries. In 2003 the U.S. Congress authorized the five-year, $\$ 15$ billion President's Emergency Plan for AIDS Relief (PEPFAR), which financed prevention, care, and treatment in fifteen countries. This law was reauthorized in 2008 for five years and will provide approximately US $\$ 48$ billion to more than 100 countries. The World Bank also began funding AIDS treatment programs in 2005 and spent approximately US $\$ 1.4$ billion on HIV/AIDS programs in Africa from 2001 to 2007. These sums dwarf the less than US\$1 billion that donors spent on global health, including HIV, in the late 1990s. Although it is difficult to gauge the impact of these resources on HIV prevention and transmission, approximately four million people receive HAART and HIV/AIDS care services today.

Developing countries can influence global drug market and price dynamics. Brazil's demand for active pharmaceutical ingredients (APIs) to produce generics locally created economies of scale for generic ARVs. This in turn contributed to declining unit costs of generic ARVs, which, with new donor funding, contributed to developing countries' demand for generic ARVs, as well as APIs. This induced new generic firms to enter the ARV market, increasing competition and further contributing to declining drug prices. This phenomenon, along with bulk purchase agreements in exchange for deep discounting from the William J. Clinton Foundation and other donors, has transformed the ARV marketplace dramatically since 2003. Formerly a high-margin, low-volume model, the ARV market has become a low-margin, high-volume model.

By encouraging public discussions on AIDS treatment costs and engaging the media and activist groups about price negotiations, Brazil promoted transparency about drug prices in developing countries. Since 2001, Indonesia, Zambia, Ghana, Mozambique, Swaziland, Malaysia, Peru, Eritrea, and Guinea have issued compulsory licenses to import or produce ARVs. Most notably, in 2006 and 2007, Thailand began issuing compulsory licenses to import generic cardiovascular and ARV drugs.

Thailand's move promoted greater transparency about new market prices for ARVs for middle-income countries; after Thailand issued a compulsory license, Brazil issued one to import generic efavirenz. This represented a departure from previous policies: before 2007, Brazil had only threatened to issue a compulsory license to induce deep discounts. Availability of new low-cost generics may have prompted Brazil's move; by 2007, generic drug companies could produce efavirenz at much lower prices than the Brazilian government could.

Shortly after Brazil's and Thailand's 2007 moves, Abbott dropped its global prices for AIDS drugs for low- and middle-income countries. This move was likely prompted by concerns that other developing countries would begin issuing compulsory licenses to import generics. Similarly, although with less public fanfare, 
other innovator companies have dropped their prices for patented medicines in recent years as generic companies lowered theirs.

\section{Current Challenges For Brazil And Other Countries}

Brazil's NAP currently faces several challenges that other developing countries will face as they expand AIDS treatment.

Rising costs of providing drugs for AIDS treatment. Although price negotiations for patented medicines saved Brazil \$1.2 billion, the cost of AIDS treatment continues to rise. From 2004 to 2005, the last year for which disaggregated price and cost data are available, the total cost of providing drugs for AIDS treatment more than doubled from US\$193 million to US $\$ 414$ million, and the per patient cost rose from US $\$ 1,220$ to US $\$ 2,577$. This might reflect several factors: AIDS patients are living longer; new therapeutic regimens are available; increasing numbers of drugs are integrated into the Brazilian treatment guidelines; and increasing numbers of people living with HIV/AIDS are receiving treatment. ${ }^{9}$

Longer life expectancy and increasing numbers of people receiving treatment highlight the NAP's success. Rising costs also reflect the Brazilian courts' interpreting the right to medicines liberally and generally ruling in favor of patient interest groups that lobby for integrating newer and more expensive drugs into treatment guidelines. Brazil's experience highlights the dilemmas of providing drugs for AIDS treatment: as patients live longer, they require (and frequently demand) new life-prolonging, patented medicines. If costly new ARVs, particularly patented ARVs, are integrated into treatment guidelines, HAART costs may continue to rise precipitously in Brazil and elsewhere. This trend might affect the middle-income countries that acknowledge IP rights for new ARVs and may matter less for low-income countries that are not yet required to do so. Total costs are nevertheless likely to rise globally as people with HIV/AIDS live longer and increasing numbers of patients receive HAART.

Cost and availability of generic and patented drugs. While generic competition and declining costs of APIs dramatically reduced generic ARV prices globally, the cost of producing generics in Brazil recently rose. Although it is unclear why these costs rose in Brazil while they declined elsewhere, Brazil has continued to produce generic drugs locally, despite the availability of cheaper generics, probably because of local political factors and the net savings of its strategy.

Few other developing countries rely on locally produced generics for AIDS treatment programs. However, donors are increasingly promoting more widespread generic drug use, and generic competition will continue to lower global ARV prices for low-income countries that do not acknowledge IP rights for drugs. In contrast with Brazil, which rapidly integrates new patented medicines into national treatment guidelines, many low-income countries, including Tanzania, Uganda, and Zambia, all with large treatment programs, wait several years to include new drugs in treatment guidelines, usually when more-affordable generics 
become available. Although competition may lead to declining prices for relatively new generic ARVs in low-income countries, new generics' prices are generally higher than those of generic ARVs launched several years ago, in part because of higher API costs for newer products. Middle-income countries such as Mexico, Malaysia, and Thailand more frequently include newer, more costly patented medicines in their guidelines and usually acknowledge IP rights for drugs. Most middle-income countries, however, do not negotiate prices and may see treatment costs rise as new generic and patented drugs are adopted.

- Foreign aid and parallel health systems. The end of World Bank lending to the NAP matters less from a fiscal standpoint than from an organizational one. Historically, this support allowed the NAP to function somewhat independently of Brazil's health ministry. The program has been insulated from budget restrictions and rigid civil service rules, and is more nimble than other Brazilian health bureaucracies. Also, the NAP attracts dedicated AIDS professionals and has been somewhat sheltered from Brazil's notorious client-patron political practices. ${ }^{10}$ The challenge with termination of loans will be whether the NAP can integrate into Brazil's broader health bureaucracy while preserving its well-managed, large-scale treatment and prevention programs.

Many developing countries' AIDS programs function independently of their national health systems, and many AIDS treatment programs have been wholly or largely financed by international donors. With increasing pressure to streamline HIV programs into health systems, other countries that rely heavily on donor funding may face even greater challenges than Brazil faces regarding sustainability and management of new, parallel health systems that are highly dependent on foreign aid.

- Implications for global drug R\&D. Critics claim that Brazil's policies undermine global IP and trading systems and assert that failing to recognize patent rights could lead to less R\&D for new HIV/AIDS drugs. It's unclear whether Brazil's actions will have this effect. To date, this seems not to have occurred: thirty-two drugs or combination therapies have been approved for treatment of HIV/AIDS by the U.S. Food and Drug Administration (FDA) since 1987, and thirteen new ARVs have been approved since 2001.

According to Pharmaceutical Research and Manufacturers of America (PhRMA), forty-six ARVs are in development, and one new application was submitted recently to the FDA. This suggests that drug companies continued to invest in drug discovery for HIV/AIDS despite dramatic changes in market dynamics and global IP disputes, perhaps because the pharmaceutical industry makes the overwhelming share of its profit margins in developed markets. However, only a few HIV/AIDS drugs are in advanced stages of development, which suggests that the pipeline for AIDS medicines may indeed be limited. Whether or not this can be attributed to declining prices in emerging markets is unclear. In the future, drug companies may weigh the risks and benefits of investing R\&D resources in HIV/ 
AIDS rather than in other diseases, such as diabetes and cancer, that may offer higher profits and pose fewer political and IP challenges.

- Local and global opportunity costs. According to a United Nations report, Brazil's federal government spent approximately US $\$ 850$ million on AIDS treatment in 2007." Some might argue that this is exorbitant for a country with AIDS prevalence less than 1 percent and that this money could have been better spent on HIV prevention or on diseases that account for much more of Brazil's disease burden, such as cancer, cardiovascular disease, or other infectious diseases. On the other hand, $\$ 850$ million is less than 3 percent of Brazil's total federal public health expenditure, and although federal AIDS spending has increased in recent years, total health spending in Brazil has risen in tandem. Moreover, Brazil's spending on drugs to treat diabetes and "exceptional illnesses," including cancer, tripled from 2001 to $2006 .^{12}$ Simply reallocating NAP resources to other health programs might not have a similar public health impact as spending on HIV/AIDS; unlike other public health bureaucracies, the NAP is known for its highly dedicated public servants and for rapidly implementing high-impact programs. Other diseases accounting for equal or greater disease burden lack the political and organizational support that propelled AIDS to the frontier of public policy interventions in Brazil.

Finally, and perhaps most importantly, although Brazil's AIDS programs have been costly, Brazil has avoided the epidemic forecast by the World Bank in 1990, when Brazil was second only to the United States in diagnosed HIV/AIDS cases. Providing AIDS treatment also seems not to have led to riskier sexual behavior or "HIV optimism" among people with HIV/AIDS in Brazil. ${ }^{13}$ Although it is impossible to prove what might have happened without treatment programs, providing treatment early in Brazil's epidemic appears to have improved HIV prevention and contributed to declining HIV incidence. ${ }^{14}$ Among other reasons, HAART lowers viral load, reducing the probability of transmitting the virus and thereby improving HIV prevention. ${ }^{15}$ Brazil's story contrasts starkly with that of South Africa, which had similar HIV prevalence in 1990 but only began providing treatment on a large scale in recent years and now has the most HIV/AIDS cases of any country.

Other developing countries, particularly low-income countries, might enjoy large foreign aid budgets and lower drug costs but may also face much higher total treatment costs because of higher AIDS prevalence and costs of developing health infrastructure. Special attention given to AIDS relative to other diseases always presents both fiscal challenges and moral dilemmas for policymakers.

Recently, several scholars and development experts have criticized growing "global AIDS exceptionality," citing burgeoning resources for global AIDS programs while highlighting the tragically neglected, cost-effective, if less sexy interventions such as vaccinations, oral rehydration therapy to combat childhood diarrhea and infant mortality, and potable water, all of which are insufficiently financed. Indeed, AIDS funding has become exceptional. These expenditures may have large opportunity costs; however, it is unclear whether or not the opportu- 
nity costs are health related. If these billions were not spent on AIDS, given the lack of historical political momentum around many other health interventions, it is unlikely that funds would have been appropriated, much less spent, on diseases of equal or greater public health importance; rather, other cost-effective health interventions might have continued to be neglected globally.

HIV/AIDS programs prompted dialogue about the importance of broader global health programs; dramatic spending increases for TB, malaria, and family planning were included in the 2008 U.S. global health bill. ${ }^{16}$ In addition, AIDS programs have positive spillover effects for broader national and local health systems. For example, they have improved broader health system and infrastructure development in Uganda and Zimbabwe and improved access to health services for marginalized populations in Argentina. The success of AIDS programs led to new programs to address neglected diseases and prompted ambitious global goals such as the 2007 Gates Foundation pledge to eradicate malaria. Investments in local drug production also have positive spillover effects; for example, Brazil's long-term investments in local drug production infrastructure recently culminated in the development of a novel fixed-dose drug combination for malaria. ${ }^{17}$ With technical assistance from Brazil's health ministry and the NAP, Mozambique recently opened a new factory to produce AIDS medicines.

Growing evidence of the feasibility, positive health impacts, positive spillover effects of AIDS treatment, and lessons learned from the global AIDS treatment movement are now used to advocate expansion of global health programs in other areas, particularly neglected diseases. Furthermore, the scale of resources devoted to HIV/AIDS changed the terms of the debate; global health advocates and policymakers now suggest increasing resources for myriad other health issues, and global health spending has finally garnered international political support. This sea change in commitments to global health stemmed, in large part, from scaling up AIDS programs and has positive, long-term policy implications for addressing other historically neglected global health interventions.

LTHOUGH B R A I I'S EXACT MODEL might not be replicated elsewhere, it
provides evidence that AIDS treatment is possible in a developing country;
it helped create economies of scale for global generic ARV markets, helped change global essential-medicines norms, and contributed to global price declines for HAART. Other countries, particularly middle-income countries, have learned much from Brazil's experience as they now negotiate deep discounts with pharmaceutical companies, benefit from tiered pricing structures, issue compulsory licenses, rely increasingly on generics, work with blossoming civil-society movements, implement new health infrastructure, and provide millions of people with AIDS treatment. Brazil's unprecedented accomplishments in AIDS treatment have profoundly influenced global AIDS and health policy. 

The authors gratefully acknowledge the U.S. Departments of State and Education for financing fieldwork related to this paper. This research was also supported by Training Grant no. T32DA13911-08 from the National Institute on Drug Abuse (NIDA) and by Grant no. P30AI042853 from the National Institute of Allergy and Infectious Diseases (NIAID). The content is solely the responsibility of the authors and does not necessarily represent the official views of NIDA, NIAID, or the National Institutes of Health. Amy Nunn receives consulting fees from the pharmaceutical company Mylan Inc.

\section{NOTES}

1. J.R. Marins et al., "Dramatic Improvement in Survival among Adult Brazilian AIDS Patients," AIDS 17, no. 11 (2003): 1675-1682; and A. de Brito et al., "Trends in Maternal-Infant Transmission of AIDS after Antiretroviral Therapy in Brazil" (in Portuguese), Revista de Saúde Pública 40 Supp. (2006): 18-22.

2. I. Dourado et al., "AIDS Epidemic Trends after the Introduction of Antiretroviral Therapy in Brazil" (in Portuguese), Revista de Saúde Pública 40 Supp. (2006): 91-97.

3. A. Nunn, The Politics and History of AIDS Treatment in Brazil (New York: Springer International, 2008).

4. Authors' interviews with Brazilian President Fernando Cardoso, Health Minister Jose Serra, and National AIDS Program Director Paulo Teixeira, 2005 and 2006.

5. Authors' interviews with Legal Aid attorneys Miriam Ventura, Ingrid Carvalho, and Rosana Del Bianco, 2005; and J. Galvão, "Brazil and Access to HIV/AIDS Drugs: A Question of Human Rights and Public Health," American Journal of Public Health 95, no. 7 (2005): 1110-1116.

6. United Nations General Assembly Special Session, "HIV/AIDS: Brazilian Response 2005/2007 Country Progress Report" (New York: UNGASS, 2008).

7. A. Nunn et al., "Evolution of Antiretroviral Drug Costs in Brazil in the Context of Free and Universal Access to AIDS Treatment," PLoS Medicine 4, no. 11 (2007): e305.

8. A. Nunn, E.D. Fonseca, and S. Gruskin, "Changing Global Essential Medicines Norms to Improve AIDS Treatment: Lessons from Brazil," Global Public Health 4, no. 2 (2008): 130-149.

9. Nunn et al., "Evolution of Antiretroviral Drug Costs."

10. A. Barry, "The Deadlock of Democracy in Brazil," in Interests, Identities, and Institutions in Comparative Politics, ed. M. Lichbach (Ann Arbor: University of Michigan Press, 2002).

11. UNGASS, "HIV/AIDS: Brazilian Response 2005/2007."

12. Departamento de Informática do SUS (DATASUS), "Gastos Para Medicamentos Excepcionais Pacientes Crônicos" (Brasilia: Ministério da Saúde, 2009); and Coordenação de Acompanhamento e Avaliação (CAA/Ministério da Saúde), "Execução Orçamentária e Financeira 2001-2005” (Brasília: CAA, 2005).

13. D. Kerrigan et al., "The Search for Social Validation and the Sexual Behavior of People Living with HIV in Rio de Janeiro, Brazil: Understanding the Role of Treatment Optimism in Context," Social Science and Medicine 62 , no. 10 (2006): 2386-2396

14. Dourado et al., "AIDS Epidemic Trends."

15. J.S. Montaner et al., "The Case for Expanding Access to Highly Active Antiretroviral Therapy to Curb the Growth of the HIV Epidemic," Lancet 368, no. 9534 (2006): 531-536.

16. The Tom Lantos and Henry J. Hyde United States Global Leadership against HIV/AIDS, Tuberculosis, and Malaria Reauthorization Act of 2008, PL 110-293: To Authorize Appropriations for Fiscal Years 2009 through 2013 to Provide Assistance to Foreign Countries to Combat HIV/AIDS, Tuberculosis, and Malaria, and for Other Purposes (2008).

17. Doctors Without Borders, "MSF Welcomes New Fixed-Dose Combination Against Malaria Developed through a Partnership between DNDI and Farmanguinhos, ASMQ Combines Artesunate (AS) and Mefloquine (MQ) in One Fixed Dose," 17 April 2008, http://www.msf.org/au/resources/position-papers html (accessed ll April 2009). 